\title{
Indicators of Understanding: What TAs Listen for in Student Responses
}

\author{
Renee Michelle Goertzen*, Rachel E. Scherr*, Andrew Elby*† \\ *Department of Physics, University of Maryland, College Park, MD 20742 \\ $\dagger$ Department of Curriculum and Instruction, University of Maryland, College Park. MD 20742
}

\begin{abstract}
Before we can develop effective, research-based professional development programs for graduate student physics TAs, we must first identify their current classroom practices and why they engage in these practices. Framing, a theoretical framework developed in sociology and linguistics, provides an analytical toolbox for examining the expectations that guide the actions and attention of individuals while teaching. We use framing to develop fine-grained analyses of two episodes of TAs teaching tutorials. Despite the differences in their behaviors, the two TAs are in a sense both doing the same thing; they organize their interactions with students around "searching for indicators" that the students understand the targeted ideas.
\end{abstract}

Keywords: teaching assistants, graduate students, framing, tutorials

PACS: 01.40.-d, 01.40.Fk

\section{INTRODUCTION}

The physics education community has devoted years to producing research-based undergraduate curricula that help students construct their own physics knowledge. While the developers of these curricula have carefully studied how material should be presented and how students should best interact with these materials, much less attention has been given to those who implement the curricula, namely the teaching assistants (TAs). Many administrators of TA professional development programs have given careful consideration to what they want TAs to do in the classroom and how to help them do that, but there has been little research on the subject to date.

An example of the limited attention given to TA instruction in published research is found in an article by Finkelstein and Pollock which details the implementation of UW tutorials at the University of Colorado in Boulder. Their account of the TA's job is "playing the role of 'learning coach,' asking guiding questions in a Socratic manner without explicitly explaining the answers"[1]. While such descriptions provide a general sense of what sorts of actions the tutorial designers expect from TAs, we need to know much more before we can understand the behavior of TAs in tutorial classrooms, what motivates it, and how it affects students. Questions that need to be answered include: What do TAs actually do in classrooms?
What do they understand their job to be? What sorts of questions do they ask, and what do they consider appropriate responses? Answering these questions can help us implement research-based curricula more effectively and provide effective TA professional development.

\section{FRAMING}

Hammer, Elby, Scherr, and Redish define a frame as "a set of expectations an individual has about the situation in which she finds herself that affect what she notices and how she acts"[2]. This definition is strongly influenced by Goffman's description of framing as a search for answers to the question of "What is it that's going on here?[3]"

An everyday example of how framing affects what an individual notices is a soccer dad at his daughter's soccer game. He could frame the game as an experience that nurtures children or as a competitive athletic event. In the first case, the father might pay attention to which children are having fun and his actions might include non-partisan applause or encouragement. In the second, he might pay attention to which team is winning and whether his daughter is playing her best and he might participate in partisan cheers or jeers. Instead of ascribing a stable belief about the purpose of children's soccer to the dad, we gain more explanatory power by focusing on how he 
frames the game at different times based on contextual cues. We think the same is true when examining how TAs frame their students' learning and their own teaching.

By using framing to analyze how TAs teach, the research question focuses attention on the variability within an individual TA. Rather than categorizing TAs as possessing certain stable beliefs, the goal is to identify the different ways TAs can behave in the classroom and the reasons why, for example, they might lecture in one instance and ask probing questions in another. In this way, we seek to describe and understand the (multiple) ways in which TAs frame their teaching rather than to provide a global characterization of individual TAs. Well-supported descriptions and explanations of a TA's actions are still generated, though those descriptions and explanations do not apply to all of the TA's interactions.

We use videotapes of TAs' classroom interactions with students as the primary data source for our explanations; interview data is then used to support, disconfirm and/or flesh out our accounts. By contrast, many studies of TAs and teachers attempt first to understand the instructor through interviews or written assignments, and then (in some cases) to compare these assessments to actual behavior.

\section{CONTEXT FOR RESEARCH}

During the fall semesters of 2006 and 2007, University of Maryland (UM) graduate students who were TAs for tutorials used in the introductory algebra-based physics class (Physics 121) were invited to participate in the study. TAs who consented had their tutorial sections videotaped. They were interviewed twice, once at the start of the semester and once at the end. TAs chosen for taping were selected because the times they taught were convenient for taping and not on the basis of their teaching or past experience. Some of the tutorials used at UM are modified versions of tutorials developed by the University of Washington Physics Education Group [4]. Others were developed at UM as part of a project to design tutorials specifically for the algebra-based course.

\section{USING FRAMING TO UNDERSTAND TA PRACTICE}

As physics graduate students go about tasks that are required of teaching assistants, they can frame their activities in different ways. One way in which TAs seem to understand their job in the tutorial classroom is as a search for indicators. These indicators could be various things, including the production of key words, a particular type of reasoning, or the correct answer. TAs ask questions of and interact with the students toward achieving this often tacit goal of the TA. When students have produced the relevant indicators, the TAs see this as evidence that the students have the necessary knowledge and the TA's job in that moment is finished. The pedagogical success of this way of framing depends on the situation and how indicative the indicators are of the desired knowledge. A detailed answer to a more challenging question might be strong evidence that the students understand the concept, while a numerical answer without additional reasoning (as detailed in the first example) is weaker evidence.

Although the situations that will be described below are an illustration of a common "focusing on indicators" frame, this does not imply that the TAs all behave in the same way. TAs have different behaviors and attitudes available to them, and they also consider different information and types of statements to be appropriate knowledge indicators. Furthermore, we would expect the context of the particular situation (which tutorial they are doing, the group of students with whom they are interacting, etc.) to encourage different behaviors within similarly framed activities.

\section{Alan: Listening for Indicator Numbers}

Alan, a first year graduate student, thought that the tutorials were doing an insufficient job of preparing students to do quantitative problems because students didn't practice converting physical situations into quantitative equations. He worried that students weren't being exposed to or gaining practice in the more important part of physics, which was the way that it uses mathematics to predict things about the world (Alan, Intro Interview p. 4).

In this example of a TA framing teaching as "focusing on indicators," Alan is listening for numerical indicators. Because he is focused on the numerical answer, he fails to notice that the students don't seem to understand the answer that they have provided, and thus that it may not be a good indicator of student knowledge.

In this next segment, a group of students are working on a part of the Newton's third law tutorial which asks them to do some calculations for a problem where a car and truck collide[5]. The students have been told that the car and truck remain in contact for 0.50 seconds before bouncing off each other and that the truck slows down by $5 \mathrm{~m} / \mathrm{s}$. The students in this clip have completed the question and called over the TA as instructed by the tutorial checkpoint. Alan begins by asking what they calculated for the truck's acceleration 
during the collision, for which the correct answer is $a=\frac{\Delta v}{\Delta t}=\frac{5 \mathrm{~m} / \mathrm{s}}{.5 \mathrm{~s}}=10 \mathrm{~m} / \mathrm{s}^{2}$.

1 S3: We have to consult a TA.

2 Alan: Yeah, sure, what's up? Uh, where are you guys?

3 S4: We're on that one.

4 Alan: You're on that one. So what did you guys get for the-

5 S3: Ten meters per second.

6 Alan: Yeah, you guys are right.

7 S1: Oh, hey! That's two.

8 Alan: You guys are right.

9 S3: All right.

10 Alan: It's just to make sure that you get it. Does that make sense?

11 S1: Hey, I was just guessing on that. Yeah!

12 Alan: ??? the truck is twice as heavy and the car is twice as light so... See where it takes you, that's the, that's the interesting thing.

13 S1 \& S4: Okay.

In this example, Alan asks for the numerical answer to the problem. When the students provide the correct answer, he does not ask them about their reasoning or how they computed that answer (line 6). While it wouldn't be unexpected for a TA to simply check on answers occasionally, without probing student reasoning, it is somewhat surprising in this instance. Student 1 conveys surprise and excitement about their correct answer in line 7, which is spoken loudly and with some astonishment, and when Alan asks if the answer makes sense, Student 1 responds that "I was just guessing on that" (line 11). In spite of this, Alan doesn't ask any further questions, but instead briefly mentions where this answer "takes you" (line 12), which may refer to the idea that this calculation helps them see why the truck and the car can experience the same force even though one is accelerated more.

In this case, it seems the indicator is the right number. Alan shows that the students have successfully indicated their knowledge to him when he repeats "You guys are right" twice after they state their numerical answer (lines 6,8).

One might argue with this interpretation by hypothesizing that Alan didn't purposefully ignore S1's exclamation that he was guessing; it might simply be the case that Alan didn't notice S1's statement. This interpretation strengthens the framing argument. Alan's attention is influenced by his framing of the situation, which in this case has led to his conclusion that the students' correct answer indicates correct understanding. That is, Alan's attention is not on S1's answer to the question that Alan has just asked, because he thinks he already knows the answer: the problem's solution makes sense to the students.

\section{Julian: Listening For Instructionally Targeted Explanations}

Julian is a first year graduate student who evaluated the tutorials in an interview as follows: "I like the whole interactive versus traditional thing. But I don't like the way they set it up. It's like, it seems like, it's um, it's bad for the students... To have this, like these problems that are so open-ended. And like, to just to like, it's, it's hard to give guidance..." (Julian Intro Interview, p. 1).

The students in the episode below are working on a problem that asks for an interpretation of a number. Several tutorials have asked students to provide interpretations of a calculated number, which is described as "a statement that tells you what the number means physically"[6]. In this example, students are told that a certain stone has a mass of 120 grams and a volume of $60 \mathrm{~cm}^{3}$. In this context, an acceptable interpretation of the number 2 would be "the number of grams in each cubic centimeter of stone."

1 Julian: So, how did you use your interpretation for the density to determine how much mass the object has?

2 S3: Ah, you mult-, er, calculate the ratio of mass over, yeah, mass over volume, and multiply the volume by the, by the density and you get the-

3 Julian: I don't know if that really uses your interpretation. That sort of more uses an equation.

4 S3: Oh, okay.

5 Julian: So you know, so you're sort of saying you know density is this, so you're trying to find a mass that satisfies this density. But that's not really using your interpretation.

6 S3: Grams and centimeters, so...

7 Julian: So, how would you go about using your interpretation?

8 S3: Well, you need the number of grams, number of grams in seven centimeters and density's, I don't know. I'm not sure how to explain it without using the equation.

9 Julian: So what is your interpretation, first of all?

10 S3: Number of grams, uh, in a cubic centimeter.

11 S2: Stuff in an amount of area.

12 Julian: Okay, so there's two grams per cubic centimeter, is that what you're saying? 
13 S3: Right, yeah.

14 Julian: So, I think it's more of a-

15 S3: Okay.

16 Julian: two is the number of grams per cubic in a cubic centimeter for an object.

17 S3: To get seven cubic centimeters, you have, there's two... two grams for every cubic centimeter.

18 S4: Sorry.

19 Julian: Right. So that would be a good way to think about it-

20 S5: Better be.

21 S4: Not anymore.

22 Julian: -Except, well, a good way to use your interpretations is that so, you have seven cubic centimeters. And for every cubic centimeters you're going to have two grams. So you're going to have two, four - seven two-gram units. So, so that the total's fourteen grams.

23 S4: Two grams for every seven centimeter group?

The first thing Julian does upon hearing Student 3's explanation of his solution is to compare it to the answer he expects. In line 3 , he tells the students that their answer does not use an interpretation, indicating that he thinks that they have not done the problem correctly. Although the students did math that could have resulted in a correct numerical answer (line 2), Julian's indicator of understanding is not simply a computationally correct answer, but one that provides reasoning in a way that the tutorial requires.

In several instances, Julian interprets students' statements with respect to the target. In line 12, he rephrases their original answer of "number of grams in a cubic centimeter" (line 10). He assumes that his restatement is the same as the original, as indicated by his question, "Is that what you're saying?" He then offers an interpretation that is closer to what he expects, "I think it's more of a..." (lines $14 \& 16$ ). When a student then repeats back Julian's interpretation (line 17), Julian hears a confirmation that the students understand what he is explaining to them.

In this case, it seems that Julian expects an instructionally targeted explanation. He makes an attempt to get that from the students, first by telling them that their answer is wrong and then by breaking the solution into smaller parts when he asks, "So what is your interpretation, first of all?" (line 9). When both of these moves fail to elicit an answer from the students that Julian would consider appropriate, he provides it for them, first by giving an example of a correct interpretation (line 16) and then by using the interpretation to answer the question. Julian interprets the students' responses as evidence of their understanding. This is a strong assumption to make, as they are simply repeating Julian's answer back to him, but as the Alan example also showed, focusing on indicators makes the TA liable to interpret a student's mention of the indicator as evidence that the student "gets it."

\section{CONCLUSIONS}

By developing case studies of how TAs frame tutorial instruction, we will learn more about the different ways TAs can approach teaching and the expectations they have about teaching and students. Focusing on indicators is just one of the ways that TAs can frame their tutorial teaching. Other ways we have seen Alan or Julian frame their job in the classroom include answering student questions, eliciting student ideas ("brainstorming"), and providing individualized "mini lectures." In future papers we plan to describe additional ways we have seen TAs frame their work.

Framing allows us to create explanations of how TAs' expectations, coupled with the context of a particular situation, lead to particular classroom behaviors. In the cases described above, the TAs' focus on indicators could indicate that they frame tutorials as a place where students gain understanding and that they expect that their job in tutorial is to verify that students have gained the appropriate knowledge.

\section{ACKNOWLEDGMENTS}

This work is supported by NSF grant REC 0529482.

\section{REFERENCES}

1. N. D. Finkelstein and S. J. Pollock, PRST: PER 1, 010101 (2005).

2. D. Hammer, A. Elby, R. E. Scherr, E. F. Redish, "Resources, Framing, and Transfer," in Transfer of Learning, edited by J. Mestre, Information Age Publishing, 2005, p. 96.

3. E. Goffman, Frame Analysis: An Essay on the Organization of Experience, Northeastern University Press, Boston, 1974, p. 8.

4. L. C. McDermott, P. S. Shaffer, and the Physics Education Group, Tutorials in Introductory Physics, Prentice Hall, Upper Saddle River, NJ,2006.

5. A. Elby et al., Maryland Tutorials in Physics Sensemaking, DVD, Funded by NSF DUE-0341447, 2007.

6. A. Elby, et al., Physics 121: Tutorials and Laboratories, Department of Physics, University of Maryland, College Park, Fall 2006 edition, Wiley Custom Services, pp. 9-2. 